\title{
External Beam Radiotherapy for Hepatocellular Carcinoma: a Review of the Current Guidelines in the East and the West
}

\author{
Sang Min Yoon \\ Department of Radiation Oncology, Asan Liver Center, Asan Medical Center, University of Ulsan College of Medicine, Seoul, Korea
}

Received Nov. 18, 2020

Revised Jan. 11, 2021

Accepted Jan. 20, 2021
The incidence of hepatocellular carcinoma (HCC) is geographically heterogeneous depending on the underlying liver disease. Moreover, the decisions and recommendations about standard treatments differ between countries, especially between the East and the West. Because of the complexity of treatment decisions for the management of HCC, a multidisciplinary approach is recommended to maximize the therapeutic efficacy. External beam radiotherapy (RT) has been increasingly used to manage $\mathrm{HCC}$ when recommended treatments cannot be applied in real-world clinical practice. However, Western guidelines for the management of HCC do not recommend RT as a treatment option due to the lack of clinical evidence. RT has often been used more in Eastern countries than in Western countries; hence, it is necessary to review both Eastern and Western guidelines for HCC treatment regarding the recommendations about RT. In this study, the comments and potential roles of external beam RT are summarized from several treatment guidelines for the management of HCC. (J Liver Cancer 2021;21:25-33)

Keywords: Hepatocellular carcinoma; Radiotherapy; Treatment; Guidelines

\section{INTRODUCTION}

Liver cancer is the sixth most common cancer and the fourth leading cause of death from cancer according to the recent global cancer statistics. ${ }^{1}$ Hepatocellular carcinoma (HCC) accounts for approximately $80 \%$ of cases of liver cancer. ${ }^{1,2}$ The incidence of HCC is geographically heterogeneous and largely depends on the underlying liver disease. ${ }^{3}$ Moreover, the decisions and recommendations about standard treatments also differ between countries, especially between

\section{Corresponding author : Sang Min Yoon}

Department of Radiation Oncology, Asan Liver Center, Asan Medical Center, University of Ulsan College of Medicine, 88 Olympic-ro 43-gil, Songpa-gu, Seoul 05505, Korea

Tel. +82-2-3010-5615, Fax. +82-2-3010-6950

E-mail; drsmyoon@amc.seoul.kr

https://orcid.org/0000-0002-5138-3051 countries in the East and West. ${ }^{3}$

Decisions about the optimal treatment for HCC are complex because many therapeutic options need to be considered based on the tumor burden, underlying hepatic function, patient performance status, and availability or applicability of specific treatment modalities. For example, not all patients with early-stage HCC can undergo curative treatments, such as hepatic resection, radiofrequency ablation (RFA), or liver transplantation (LT), because of various clinical conditions. Moreover, tumor recurrences are frequently observed after initial treatment; however, there are no clear recommendations or guidelines for the management of recurrent HCC. Due to this complexity of treatment decisions, a multidisciplinary approach is recommended to maximize therapeutic efficacy. ${ }^{4}$

In recent times, technologies for external beam radiothera- 
py (RT), including 4-dimensional computed tomography (CT), strategies for management of respiratory motion, intensity-modulated RT, particle therapy, and image-guided RT, have advanced rapidly. ${ }^{5,6}$ Moreover, based on the results of many clinical studies, HCC is considered a radiosensitive malignancy. ${ }^{7}$ Therefore, RT has been increasingly used in the management of HCC when the recommended treatments cannot be applied in real-world clinical practice. Since the purpose of RT can be varied, from curative to palliative depending on the patient's disease status, RT might play a role as a treatment option for all stages of HCC. ${ }^{6,89}$ However, the Western guidelines for HCC do not recommend RT as a treatment option because of the lack of clinical evidence. ${ }^{10,11}$ RT has often been used more frequently in Eastern countries than in Western countries. Hence, it is necessary to review the Eastern and Western treatment guidelines for HCC regarding their recommendations for RT to understand the current status of RT in the management of HCC. Here, the comments and potential roles of external beam RT are summarized from several treatment guidelines for the management of HCC.

\section{TREATMENT GUIDELINES IN ASIA}

Several guidelines or consensus statements exist for the diagnosis and management of HCC in organizations and countries in the Asian region. In this section, the recently updated recommendations related to external beam RT in these guidelines are summarized in Table 1.

\section{Asia-Pacific clinical practice guidelines}

The first version of the Asia-Pacific Association for the Study of the Liver (APASL) guidelines on HCC was published in 2010, and a recently updated version was published in $2017,{ }^{12}$ in which the guidelines summarized the background, indications, contraindications, efficacy, complications, and response assessment of RT. This updated version describes the growing evidence of the efficacy of stereotactic body RT (SBRT) for small HCC and charged-particle RT for large HCC or portal vein tumor thrombus. ${ }^{13-16}$ However, be- cause of the lack of strong evidence to support RT for patients with HCC, the APASL guidelines did not recommend RT as standard therapy, although SBRT and proton beam were reasonable options for patients who had failed to respond to other local therapies (grading of evidence: low or very low quality; grading of recommendation: weak). Nonetheless, RT might be a promising treatment option for HCC because of the radiosensitivity of HCC and recent advancements in RT techniques. ${ }^{12}$

\section{Practice guidelines for the management of HCC in Korea}

The first version of the Korean Liver Cancer Study Group (KLCSG)-National Cancer Center (NCC) Korea practice guidelines for the management of HCC was announced in 2003, and the 4th version of the Korean Liver Cancer Association (KLCA, formerly KLCSG)-NCC Korea practice guidelines was published in 2018. ${ }^{17}$ According to the guidelines, there are six recommendations related to the use of RT in the management of HCC.

First, external beam RT requires computerized RT planning using CT and is feasible for patients with HCC if their liver function is Child-Pugh class A or B7 and the irradiated total liver volume receiving $\leq 30 \mathrm{~Gy}$ is $\geq 40 \%$ (quality of evidence: moderate; strength of recommendation: strong). ${ }^{17,18}$ Second, RT can be considered for patients with HCC ineligible for surgical resection, LT, other local modalities, and transarterial chemoembolization (TACE) (quality of evidence: low; strength of recommendation: strong). In this category, hypofractionated RT, such as SBRT or particle therapy, can be actively considered based on recent favorable clinical results if the tumor burden is not widespread. ${ }^{15,16,19-22}$ Third, RT can be performed in patients with HCC who show an incomplete response to TACE (quality of evidence: moderate; strength of recommendation: weak). The addition of RT after incomplete TACE resulted in a complete response rate of $20-25 \% .{ }^{23,24}$ Fourth, RT can be performed in patients with HCC with portal vein tumor thrombus when the dosevolume criteria are met (quality of evidence: moderate; strength of recommendation: weak) with those reported in 
many previous retrospective studies. ${ }^{25-30}$ Moreover, the combination therapy with conventional TACE and RT was strongly recommended (quality of evidence: moderate; strength of recommendation: strong) for patients with localized tumors and portal vein tumor thrombus, based on the results of a recent single-center randomized controlled trial in Korea. ${ }^{31}$ Fifth, RT can be performed to alleviate symptoms caused by metastases (quality of evidence: moderate; strength of recommendation: strong) according to many studies on the role of RT in patients with lymph node metastases, ${ }^{32-34}$ adrenal metastases, ${ }^{35}$ lung metastases, ${ }^{36}$ brain metastases, ${ }^{37,38}$ and bone metastases, including spinal cord compression. ${ }^{39-42}$ Finally, the updated guidelines also included second-line therapies for recurrent HCC: RT can be considered in patients with HCC who have recurrent or refractory disease after local therapy in this regard (quality of evidence: low; strength of recommendation: strong). ${ }^{17}$

Although the quality of evidence is moderate to low, the

Table 1. Summary of the recommendations regarding radiotherapy in the guidelines and consensus statements for the management of hepatocellular carcinoma

\begin{tabular}{|c|c|c|c|c|c|}
\hline Affiliation & Country & Year & Evidence of RT & Recommendation of RT & Potential role of RT in clinical situations \\
\hline APASL & $\begin{array}{l}\text { Multinational } \\
\text { (Asia) }\end{array}$ & 2017 & Low/very low & Weak & $\begin{array}{l}\text { - SBRT for small HCC } \\
\text { - Particle therapy for large HCC or PVTT }\end{array}$ \\
\hline KLCA-NCC & Korea & 2018 & Low/moderate & Weak/strong & $\begin{array}{l}\text { - RT for HCC ineligible for surgery, LT, other LRTs } \\
\text { - RT for incomplete response to TACE } \\
\text { - RT for HCC with PVTT (combined with TACE) } \\
\text { - Palliative RT for metastases }\end{array}$ \\
\hline JSH & Japan & 2017 & - & Weak & $\begin{array}{l}\text { - SBRT for HCCs not indications for other LRTs } \\
\text { - Particle therapy for HCCs not eligible for other LRTs } \\
\text { - 3D-CRT when SBRT and particle therapy are not eligible } \\
\text { (PVTT, unresectable HCC) }\end{array}$ \\
\hline TLCA & Taiwan & 2015 & Level 2 & Recommended & $\begin{array}{l}\text { - Medically inoperable, refusal of standard treatment, } \\
\text { bridge to transplant, unsuitable/refractory to TACE, } \\
\text { localized HCC with symptoms, PVTT, symptomatic } \\
\text { metastasis or oligo-metastasis in all BCLC stages }\end{array}$ \\
\hline \multirow[t]{2}{*}{ NHFPC } & China & 2017 & Level 3 & - & $\begin{array}{l}\text { - RT for PVTT, IVCTT or extrahepatic metastases, bridge to } \\
\text { LT, relieving symptoms } \\
\text { - Adjuvant RT for centrally located tumors with narrow } \\
\text { surgical margins }\end{array}$ \\
\hline & Hong Kong & 2015 & Level 4/5 & - & $\begin{array}{l}\text { - RT for effective local control, a viable portion for } \\
\text { unresectable HCC, combined with TACE for unresectable } \\
\text { HCC } \\
\text { - SBRT as an alternative to ablation and a bridging therapy } \\
\text { before LT }\end{array}$ \\
\hline AASLD & United States & 2018 & Level 2 & - & - SBRT as an alternative to thermal ablation \\
\hline EASL & $\begin{array}{l}\text { Multinational } \\
\text { (Europe) }\end{array}$ & 2018 & Low & Weak & $\begin{array}{l}\text { - RT in combination with TACE } \\
\text { - SBRT as a bridge to LT } \\
\text { - RT for PVTT } \\
\text { - Palliative RT for pain, impending fracture }\end{array}$ \\
\hline ESMO & $\begin{array}{l}\text { Multinational } \\
\text { (Europe) }\end{array}$ & 2018 & Level 3 & $B / C$ & $\begin{array}{l}\text { - SBRT as alternatives for the ablation } \\
\text { - Palliative RT for bone metastases }\end{array}$ \\
\hline
\end{tabular}

RT, radiotherapy; APASL, Asia-Pacific Association for the Study of the Liver; SBRT, stereotactic body radiotherapy; HCC, hepatocellular carcinoma; PVTT, portal vein tumor thrombus; KLCA-NCC, Korean Liver Cancer Association-National Cancer Center; LT, liver transplantation; LRT, locoregional therapy; TACE, transarterial chemoembolization; JSH, Japan Society of Hepatology; 3D-CRT, 3-dimensional conformal radiotherapy; TLCA, Taiwan Liver Cancer Association; BCLC, Barcelona Clinic Liver Cancer; NHFPC, National Health and Family Planning Commission; IVCTT, inferior vena cava tumor thrombus; AASLD, American Association for the Study of Liver Diseases; EASL, European Association for the Study of the Liver; ESMO, European Society for Medical Oncology. 
recommendation of external beam RT for several clinical situations as a treatment modality for HCC is strong according to the KLCA-NCC Korea practice guidelines. Interestingly, RT alone (stage II by the modified Union for International Cancer Control [UICC] staging) and combined TACE and RT (stage III by the modified UICC staging) were described as some of the best treatment options in the first-line treatment recommendations from the 2018 KLCA-NCC Korea practice guidelines for patients with HCC, Child-Pugh class A, no portal hypertension, and Eastern Cooperative Oncology Group performance status 0 or $1 .^{17}$

\section{Clinical practice guidelines for HCC in Japan}

The first edition of the clinical practice guidelines for HCC was compiled by the Japan Society of Hepatology (JSH) in 2005. The 4 th version of the JSH-HCC guidelines was published on the JSH website (https://www.jsh.or.jp/English/) and in a recent article that highlighted the important revisions in the recommendation and algorithms. ${ }^{43}$ They classified RT for HCC into ablative RT for achieving local cure, such as SBRT and particle therapy, and adjuvant RT for supporting surgery and TACE, such as 3-dimensional conformal RT (3D-CRT). ${ }^{44}$ From this perspective, the guidelines used clinical questions related to SBRT, particle therapy, and 3DCRT in their chapter on RT with the background, scientific statement, and explanation for each clinical question.

In the clinical question about whether SBRT can be recommended as a treatment for HCC, the guidelines mentioned that SBRT might be performed for HCC lesions in which other types of locoregional therapies are not indicated and for recurrent HCC after various locoregional therapies (grading of recommendation: weak). In the second clinical question about the efficacy of particle therapy in HCC, the guidelines stated that particle therapy (proton therapy and heavy particle therapy) might be performed for HCC for which other types of locoregional therapies are not indicated (grading of recommendation: weak). For the last question, which was about the recommendation for $3 \mathrm{D}-\mathrm{CRT}$, the guidelines mentioned that 3D-CRT might be performed when SBRT and particle therapy are difficult to perform in patients who are not candidates for other standard treatments because of the presence of portal vein tumor thrombus, unresectable HCC, or internal complications (grading of recommendation: weak). ${ }^{44}$ Unfortunately, the guidelines recommend RT as an alternative treatment only when other locoregional therapies cannot be performed in various situations. In their special report of the 2019 update, the guidelines described that RT is recommended for the management of painful bone metastasis and brain metastasis. ${ }^{43}$

\section{Consensus guidelines for HCC in Taiwan}

The Taiwan Liver Cancer Association and the Gastroenterological Society of Taiwan initiated work on the management consensus for HCC using a multidisciplinary and evidence-based approach and presented the final statement in $2015{ }^{45}$ There are four statements about the recommendations of RT in patients with HCC.

First, RT might be recommended for patients with Barcelona Clinic Liver Cancer (BCLC) stage A in the following situations: 1) HCC inaccessible for percutaneous ablative therapies; 2) medically inoperable status; 3 ) refusal to receive standard treatment; and 4) as a bridge therapy until liver transplant (agreement: 96\%; evidence: 2; recommendation: B). ${ }^{8,46-48}$ Second, RT might be recommended for patients with BCLC stage B in the following situations: 1) HCC inaccessible/unsuitable for TACE; 2) refractory to TACE; 3) consolidate TACE (under conditions 1) and 2)); 4) as a bridge therapy until liver transplant (under conditions 1) and 2)); and 5) localized tumor (of multiple) with symptoms or threat to the liver reserve (agreement: 95.8\%; evidence: 2; recommendation: B). ${ }^{49,50}$ Third, RT might be recommended for patients with BCLC stage $\mathrm{C}$ in the following situations: 1) presence of portal vein tumor thrombus (combined modalities with TACE or sorafenib); 2) HCC unsuitable/refractory to TACE; and 3 ) localized tumor (of multiple) with symptoms or threat to liver reserve (agreement: 100\%; evidence: 2; recommendation: B). ${ }^{28,51,52}$ Finally, RT might be recommended for patients with BCLC stage D with symptomatic metastasis or oligo-metastasis (agreement: 100\%; evidence: 2; recommendation: B)..$^{36,53}$ The guidelines also mentioned radiation-in- 
duced damages to the liver and adjacent luminal gastrointestinal structures and recommended a fine balance of an adequate radiation dose to control HCC while avoiding toxicity after RT. ${ }^{45}$

\section{Guidelines for primary liver cancer in China}

Guidelines for the diagnosis and treatment of primary liver cancer in China (2017 edition) included the official recommendations by the National Health and Family Planning Commission of the People's Republic of China about the surveillance, diagnosis, staging, and treatment of HCC. ${ }^{54}$ They suggested the following indications for external beam RT: 1) palliative RT for patients with stage IIIa and IIIb (staging by the Chinese staging system) HCC with tumor emboli in the portal vein/inferior vena cava or extrahepatic metastases; 2) bridge to LT; 3 ) relief of symptoms, such as pain, obstruction, or bleeding, and controlling tumor progression in patients with extrahepatic metastases; 4) postoperative adjuvant RT for centrally located tumors with narrow surgical margins $(\leq 1 \mathrm{~mm})$; these were based on published references. ${ }^{34,39,50,55,56}$ However, all the suggested indications had a low level of clinical evidence (evidence level 3). Interestingly, the guidelines also described how to define the target volumes in various circumstances, evaluation of respiratory liver motion, and use of multimodal imaging tools during the simulation process. ${ }^{54}$ Moreover, the prescription and tolerance doses of the liver and surrounding gastrointestinal tracts were also mentioned in the guidelines. ${ }^{54}$ However, there is no consensus on the target volume delineation or radiation dose prescription in RT for HCC, and careful determination of the target volume and radiation dose are necessary during RT in patients with HCC.

\section{Consensus recommendations on the man- agement of $\mathrm{HCC}$ in Hong Kong}

A multidisciplinary group of Hong Kong clinicians published a consensus of treatment recommendations on the management of HCC considering the most current evidence pertaining to treatment modalities for HCC and the latest opinion of practicing clinicians engaged in treating HCC in $2015 .^{57}$ In the section on external RT, three statements were summarized as follows: 1) high-precision RT offers effective local control of selected HCC confined to the liver, with an acceptable toxicity profile in patients with Child-Pugh A cirrhosis (level 4 according to the 2011 Oxford criteria); 2) high-precision RT is a viable option for unresectable HCC, ineligible for or refractory to TACE or other locoregional therapies (level 4); 3) high-precision RT may be combined with TACE for unresectable HCC; however, the optimal sequencing and timing are not known, and the survival benefit is uncertain (level 4). ${ }^{57}$ This consensus cited some relevant references in the section on external RT. ${ }^{28,58-62}$ All statements contained slightly unspecific comments about the role of RT.

Recently, they published a new consensus document to update the 2015 recommendations with a focus on the treatment of unresectable HCC. ${ }^{63}$ In this update, the statement on external RT focused mainly on SBRT as follows: 1) SBRT is an acceptable option for unresectable HCC (up to five lesions) (level 4); 2) SBRT can be considered in patients with limited liver reserve (up to Child-Pugh grade B8); 3) SBRT can be an alternative to ablation for tumors close to the major blood vessels or biliary tract (level 5); 4) local control can be achieved by SBRT with limited toxicity (level 4); 5) SBRT can be considered as a bridging therapy before LT (level 4). ${ }^{63}$

\section{TREATMENT GUIDELINES IN WESTERN COUNTRIES}

The recently updated guidelines for the diagnosis and management of HCC from organizations in Western countries are reviewed below to summarize the recommendations of external beam RT for HCC (Table 1).

\section{Practice guidance by the American Associa- tion for the Study of Liver Diseases}

The updated 2018 practice guidance by the American Association for the Study of Liver Diseases (AASLD) provided a data-supported approach to the diagnosis, staging, and treatment of patients with HCC. ${ }^{11}$ Although the committee 
classified SBRT as a noncurative therapy, it was considered as an alternative to thermal ablation in patients, mostly those within the Milan criteria with the relevant references. ${ }^{16,22,64}$ In addition, SBRT was also included as a therapeutic option for BCLC stage A patients in the treatment recommendations diagram (level of evidence: 2 ). ${ }^{11}$ This can be considered as a significant change in the perception of RT compared to the previous 2010 AASLD practice guidelines. ${ }^{65}$

\section{Practice guidelines by the European Asso- ciation for the Study of the Liver}

An updated version of practice guidelines for the management of HCC by the European Association for the Study of the Liver was published in 2018. ${ }^{10}$ There is a short review of the potential role of RT in combination with TACE or other intra-arterial treatments in the external RT section. ${ }^{66,67}$ SBRT can be used as a bridge to LT with drop-out and survival rates comparable to those of TACE and RFA from the time of listing. ${ }^{64}$ In addition, it has been mentioned that patients with portal vein tumor thrombus are considered a good target with some cases of secondary LT. ${ }^{26,68}$ However, the guidelines conclude that external beam RT is under investigation, and there is no robust evidence to support this therapeutic approach in the summary of recommendations (evidence low; recommendation weak). ${ }^{10}$ There is also a short comment in the palliative and best supportive care section about palliative RT for pain caused by well-identified bone metastasis or lytic bone metastasis, which is considered at high risk of spontaneous fracture, especially due to body weight. ${ }^{10}$

\section{European Society for Medical Oncology clini- cal practice guidelines}

In the high conformal, high dose rate radioablation section, there are two short comments about RT in the management of HCC. ${ }^{69}$ First, SBRT might be considered as an alternative for the ablation of tumors with a high risk of local failure after thermal ablation due to the location (level of evidence: III; grades of recommendation: C). Second, RT can be used to control pain in patients with bone metastases (lev- el of evidence: III; grades of recommendation: B). However, there is no recommendation for RT in the management of advanced-stage HCC.

\section{CONCLUSION}

External beam RT has been frequently used in the Asian region, and observations on the use of RT are described in much more detail in Asian guidelines. RT is not considered an established treatment modality for HCC because of the low level of clinical evidence. Despite this low level of evidence, it is noteworthy that SBRT is mentioned as an alternative to thermal ablation and a bridge to LT in the recent Western treatment guidelines. The recommendation levels for the use of RT are weak in the Western guidelines. Even in the Asian guidelines, the recommendations are not consistent according to the consensus of any organization or country. The utility of RT in all stages of HCC might increase in the future because of the recent advances in RT techniques and clinical studies on RT for HCC. In addition, studies focusing on detailed clinical situations can also provide good evidence to support the role of RT in HCC. A more definitive role of external beam RT in HCC will be identified from the results of several ongoing prospective trials.

\section{ETHICS APPROVAL}

This review was exempted from the Institutional Review Board approval in accordance with the regulations.

\section{ACKNOWLEDGMENTS}

This work was supported by the Korean Liver Cancer Association Research Award.

\section{AUTHOR CONTRIBUTIONS}

The author contributed solely to this article. 


\section{Conflicts of Interest}

The authors declare no conflicts of interest relevant to this article.

\section{REFERENCES}

1. Bray F, Ferlay J, Soerjomataram I, Siegel RL, Torre LA, Jemal A. Global cancer statistics 2018: GLOBOCAN estimates of incidence and mortality worldwide for 36 cancers in 185 countries. CA Cancer J Clin 2018;68:394-424.

2. Zhu RX, Seto WK, Lai CL, Yuen MF. Epidemiology of hepatocellular carcinoma in the Asia-Pacific region. Gut Liver 2016;10:332-339.

3. Choo SP, Tan WL, Goh BKP, Tai WM, Zhu AX. Comparison of hepatocellular carcinoma in Eastern versus Western populations. Cancer 2016;122:3430-3446.

4. Sinn DH, Choi GS, Park HC, Kim JM, Kim H, Song KD, et al. Multidisciplinary approach is associated with improved survival of hepatocellular carcinoma patients. PLoS One 2019;14:e0210730.

5. Keane FK, Hong TS. Role and future directions of external beam radiotherapy for primary liver cancer. Cancer Control 2017;24:1073274817729242.

6. Park HC, Yu JI, Cheng JC, Zeng ZC, Hong JH, Wang ML, et al. Consensus for radiotherapy in hepatocellular carcinoma from The 5th Asia-Pacific Primary Liver Cancer Expert Meeting (APPLE 2014): current practice and future clinical trials. Liver Cancer 2016;5:162174.

7. Bang A, Dawson LA. Radiotherapy for HCC: ready for prime time? JHEP Rep 2019;1:131-137.

8. Dawson LA. Overview: Where does radiation therapy fit in the spectrum of liver cancer local-regional therapies? Semin Radiat Oncol 2011;21:241-246.

9. Yu Y, Feng M. Radiotherapy for hepatocellular carcinoma. Semin Radiat Oncol 2018;28:277-287.

10. European Association for the Study of the Liver. European Association for the Study of the Liver. EASL clinical practice guidelines: management of hepatocellular carcinoma. J Hepatol 2018;69:182236.

11. Marrero JA, Kulik LM, Sirlin CB, Zhu AX, Finn RS, Abecassis MM, et al. Diagnosis, staging, and management of hepatocellular carcinoma: 2018 practice guidance by the American Association for the Study of Liver Diseases. Hepatology 2018;68:723-750.

12. Omata M, Cheng AL, Kokudo N, Kudo M, Lee JM, Jia J, et al. AsiaPacific clinical practice guidelines on the management of hepatocellular carcinoma: a 2017 update. Hepatol Int 2017;11:317-370.

13. Chiba T, Tokuuye K, Matsuzaki Y, Sugahara S, Chuganji Y, Kagei K, et al. Proton beam therapy for hepatocellular carcinoma: a retrospective review of 162 patients. Clin Cancer Res 2005;11:3799-3805.
14. Sugahara S, Oshiro Y, Nakayama H, Fukuda K, Mizumoto M, Abei $M$, et al. Proton beam therapy for large hepatocellular carcinoma. Int J Radiat Oncol Biol Phys 2010;76:460-466.

15. Takeda A, Sanuki N, Tsurugai Y, Iwabuchi S, Matsunaga K, Ebinuma $\mathrm{H}$, et al. Phase 2 study of stereotactic body radiotherapy and optional transarterial chemoembolization for solitary hepatocellular carcinoma not amenable to resection and radiofrequency ablation. Cancer 2016;122:2041-2049.

16. Yoon SM, Lim YS, Park MJ, Kim SY, Cho B, Shim JH, et al. Stereotactic body radiation therapy as an alternative treatment for small hepatocellular carcinoma. PLoS One 2013;8:e79854.

17. Korean Liver Cancer Association, National Cancer Center. 2018 Korean Liver Cancer Association-National Cancer Center Korea Practice Guidelines for the management of hepatocellular carcinoma. Gut Liver 2019;13:227-299.

18. Kim TH, Kim DY, Park JW, Kim SH, Choi JI, Kim HB, et al. Dosevolumetric parameters predicting radiation-induced hepatic toxicity in unresectable hepatocellular carcinoma patients treated with three-dimensional conformal radiotherapy. Int J Radiat Oncol Biol Phys 2007;67:225-231.

19. Hong TS, Wo JY, Yeap BY, Ben-Josef E, McDonnell El, Blaszkowsky LS, et al. Multi-institutional phase II study of high-dose hypofractionated proton beam therapy in patients with localized, unresectable hepatocellular carcinoma and intrahepatic cholangiocarcinoma. J Clin Oncol 2016;34:460-468.

20. Kang JK, Kim MS, Cho CK, Yang KM, Yoo HJ, Kim JH, et al. Stereotactic body radiation therapy for inoperable hepatocellular carcinoma as a local salvage treatment after incomplete transarterial chemoembolization. Cancer 2012;118:5424-5431.

21. Kim TH, Park JW, Kim YJ, Kim BH, Woo SM, Moon SH, et al. Phase I dose-escalation study of proton beam therapy for inoperable hepatocellular carcinoma. Cancer Res Treat 2015;47:34-45.

22. Wahl DR, Stenmark MH, Tao Y, Pollom EL, Caoili EM, Lawrence TS, et al. Outcomes after stereotactic body radiotherapy or radiofrequency ablation for hepatocellular carcinoma. J Clin Oncol 2016;34:452-459.

23. Choi C, Koom WS, Kim TH, Yoon SM, Kim JH, Lee HS, et al. A prospective phase 2 multicenter study for the efficacy of radiation therapy following incomplete transarterial chemoembolization in unresectable hepatocellular carcinoma. Int J Radiat Oncol Biol Phys 2014;90:1051-1060.

24. Oh D, Lim DH, Park HC, Paik SW, Koh KC, Lee JH, et al. Early three-dimensional conformal radiotherapy for patients with unresectable hepatocellular carcinoma after incomplete transcatheter arterial chemoembolization: a prospective evaluation of efficacy and toxicity. Am J Clin Oncol 2010;33:370-375.

25. Han KH, Seong J, Kim JK, Ahn SH, Lee DY, Chon CY. Pilot clinical trial of localized concurrent chemoradiation therapy for locally 
advanced hepatocellular carcinoma with portal vein thrombosis. Cancer 2008;113:995-1003.

26. Im JH, Yoon SM, Park HC, Kim JH, Yu JI, Kim TH, et al. Radiotherapeutic strategies for hepatocellular carcinoma with portal vein tumour thrombosis in a hepatitis B endemic area. Liver Int 2017;37:90-100.

27. Koo JE, Kim JH, Lim YS, Park SJ, Won HJ, Sung KB, et al. Combination of transarterial chemoembolization and three-dimensional conformal radiotherapy for hepatocellular carcinoma with inferior vena cava tumor thrombus. Int J Radiat Oncol Biol Phys 2010;78:180-187.

28. Yoon SM, Lim YS, Won HJ, Kim JH, Kim KM, Lee HC, et al. Radiotherapy plus transarterial chemoembolization for hepatocellular carcinoma invading the portal vein: long-term patient outcomes. Int J Radiat Oncol Biol Phys 2012;82:2004-2011.

29. Yu Jl, Park HC, Lim DH, Park W, Yoo BC, Paik SW, et al. Prognostic index for portal vein tumor thrombosis in patients with hepatocellular carcinoma treated with radiation therapy. J Korean Med Sci 2011;26:1014-1022.

30. Yu JI, Park JW, Park HC, Yoon SM, Lim DH, Lee JH, et al. Clinical impact of combined transarterial chemoembolization and radiotherapy for advanced hepatocellular carcinoma with portal vein tumor thrombosis: an external validation study. Radiother Oncol 2016;118:408-415.

31. Yoon SM, Ryoo BY, Lee SJ, Kim JH, Shin JH, An JH, et al. Efficacy and safety of transarterial chemoembolization plus external beam radiotherapy vs sorafenib in hepatocellular carcinoma with macroscopic vascular invasion: a randomized clinical trial. JAMA Oncol 2018;4:661-669.

32. Kim Y, Park HC, Yoon SM, Kim TH, Lee J, Choi J, et al. Prognostic group stratification and nomogram for predicting overall survival in patients who received radiotherapy for abdominal lymph node metastasis from hepatocellular carcinoma: a multi-institutional retrospective study (KROG 15-02). Oncotarget 2017:8:94450-94461.

33. Yoon SM, Kim JH, Choi EK, Ahn SD, Lee SW, Yi BY, et al. Radioresponse of hepatocellular carcinoma-treatment of lymph node metastasis. Cancer Res Treat 2004;36:79-84.

34. Zeng ZC, Tang ZY, Fan J, Qin LX, Ye SL, Zhou J, et al. Consideration of role of radiotherapy for lymph node metastases in patients with HCC: retrospective analysis for prognostic factors from 125 patients. Int J Radiat Oncol Biol Phys 2005;63:1067-1076.

35. Jung J, Yoon SM, Park HC, Nam TK, Seong J, Chie EK, et al. Radiotherapy for adrenal metastasis from hepatocellular carcinoma: a multi-institutional retrospective study (KROG 13-05). PLoS One 2016;11:e0152642.

36. Jiang W, Zeng ZC, Zhang JY, Fan J, Zeng MS, Zhou J. Palliative radiation therapy for pulmonary metastases from hepatocellular carcinoma. Clin Exp Metastasis 2012;29:197-205.
37. Park Y, Kim KS, Kim K, Chie EK, Kim JH, Kim JS, et al. Nomogram prediction of survival in patients with brain metastases from hepatocellular carcinoma treated with whole-brain radiotherapy: a multicenter retrospective study. J Neurooncol 2015;125:377-383.

38. Wang S, Wang A, Lin J, Xie Y, Wu L, Huang H, et al. Brain metastases from hepatocellular carcinoma: recent advances and future avenues. Oncotarget 2017:8:25814-25829.

39. He J, Zeng ZC, Tang ZY, Fan J, Zhou J, Zeng MS, et al. Clinical features and prognostic factors in patients with bone metastases from hepatocellular carcinoma receiving external beam radiotherapy. Cancer 2009;115:2710-2720.

40. Jung IH, Yoon SM, Kwak J, Park JH, Song SY, Lee SW, et al. High-dose radiotherapy is associated with better local control of bone metastasis from hepatocellular carcinoma. Oncotarget 2017;8:15182-15192.

41. Rades D, Dahlke M, Janssen S, Gebauer N, Bartscht T. Radiation therapy for metastatic spinal cord compression in patients with hepatocellular carcinoma. In Vivo 2015;29:749-752.

42. Seong J, Koom WS, Park HC. Radiotherapy for painful bone metastases from hepatocellular carcinoma. Liver Int 2005;25:261-265.

43. Kokudo N, Takemura N, Hasegawa K, Takayama T, Kubo S, Shimada $M$, et al. Clinical practice guidelines for hepatocellular carcinoma: The Japan Society of Hepatology 2017 (4th JSH-HCC guidelines) 2019 update. Hepatol Res 2019;49:1109-1113.

44. The Japan Society of Hepatology. Clinical Practice Guidelines for Hepatocellular Carcinoma 2017 [Internet]. Tokyo (JP): The Japan Society of Hepatology; [cited 2020 Feb 10]. Available from: http:// www.jsh.or.jp/English/guidelines_en/Guidelines_for_hepatocellular_carcinoma_2017.

45. Surveillance group, Diagnosis group, Staging group, Surgery group, Local ablation group, TACE/TARE/HAl group, et al. Management consensus guideline for hepatocellular carcinoma: 2016 updated by the Taiwan Liver Cancer Association and the Gastroenterological Society of Taiwan. J Formos Med Assoc 2018;117:381-403.

46. Andolino DL, Johnson CS, Maluccio M, Kwo P, Tector AJ, Zook J, et al. Stereotactic body radiotherapy for primary hepatocellular carcinoma. Int J Radiat Oncol Biol Phys 2011;81:e447-e453.

47. Kwon JH, Bae SH, Kim JY, Choi BO, Jang HS, Jang JW, et al. Longterm effect of stereotactic body radiation therapy for primary hepatocellular carcinoma ineligible for local ablation therapy or surgical resection. Stereotactic radiotherapy for liver cancer. BMC Cancer 2010;10:475.

48. O'Connor JK, Trotter J, Davis GL, Dempster J, Klintmalm GB, Goldstein RM. Long-term outcomes of stereotactic body radiation therapy in the treatment of hepatocellular cancer as a bridge to transplantation. Liver Transpl 2012;18:949-954.

49. Cheng JC, Chuang VP, Cheng SH, Huang AT, Lin YM, Cheng TI, et al. Local radiotherapy with or without transcatheter arterial 
chemoembolization for patients with unresectable hepatocellular carcinoma. Int J Radiat Oncol Biol Phys 2000;47:435-442.

50. Meng MB, Cui YL, Lu Y, She B, Chen Y, Guan YS, et al. Transcatheter arterial chemoembolization in combination with radiotherapy for unresectable hepatocellular carcinoma: a systematic review and meta-analysis. Radiother Oncol 2009;92:184-194.

51. Chen SW, Lin LC, Kuo YC, Liang JA, Kuo CC, Chiou JF. Phase 2 study of combined sorafenib and radiation therapy in patients with advanced hepatocellular carcinoma. Int J Radiat Oncol Biol Phys 2014;88:1041-1047.

52. Huang YJ, Hsu HC, Wang CY, Wang CJ, Chen HC, Huang EY, et al. The treatment responses in cases of radiation therapy to portal vein thrombosis in advanced hepatocellular carcinoma. Int J Radiat Oncol Biol Phys 2009;73:1155-1163.

53. Hawkins MA, Dawson LA. Radiation therapy for hepatocellular carcinoma: from palliation to cure. Cancer 2006;106:1653-1663.

54. Zhou J, Sun HC, Wang Z, Cong WM, Wang JH, Zeng MS, et al. Guidelines for diagnosis and treatment of primary liver cancer in China (2017 edition). Liver Cancer 2018;7:235-260.

55. Wang WH, Wang Z, Wu JX, Zhang T, Rong WQ, Wang LM, et al. Survival benefit with IMRT following narrow-margin hepatectomy in patients with hepatocellular carcinoma close to major vessels. Liver Int 2015;35:2603-2610.

56. Zeng ZC, Fan J, Tang ZY, Zhou J, Qin LX, Wang JH, et al. A comparison of treatment combinations with and without radiotherapy for hepatocellular carcinoma with portal vein and/or inferior vena cava tumor thrombus. Int J Radiat Oncol Biol Phys 2005;61:432443.

57. Poon RT, Cheung TT, Kwok PC, Lee AS, Li TW, Loke KL, et al. Hong Kong consensus recommendations on the management of hepatocellular carcinoma. Liver Cancer 2015;4:51-69.

58. Chan LC, Chiu SK, Chan SL. Stereotactic radiotherapy for hepatocellular carcinoma: report of a local single-centre experience. Hong Kong Med J 2011;17:112-118.

59. Honda Y, Kimura T, Aikata H, Kobayashi T, Fukuhara T, Masaki K, et al. Stereotactic body radiation therapy combined with transcatheter arterial chemoembolization for small hepatocellular carcinoma. J Gastroenterol Hepatol 2013;28:530-536.

60. Law AL, Ng WT, Lee MC, Chan AT, Fung KH, Li F, et al. Treat- ment of primary liver cancer using highly-conformal radiotherapy with kV-image guidance and respiratory control. Radiother Oncol 2012;102:56-61.

61. Tang QH, Li AJ, Yang GM, Lai EC, Zhou WP, Jiang ZH, et al. Surgical resection versus conformal radiotherapy combined with TACE for resectable hepatocellular carcinoma with portal vein tumor thrombus: a comparative study. World I Surg 2013;37:1362-1370.

62. Xu LT, Zhou ZH, Lin JH, Chen Z, Wang K, Wang P, et al. Clinical study of transarterial chemoembolization combined with 3-dimensional conformal radiotherapy for hepatocellular carcinoma. Eur J Surg Oncol 2011;37:245-251.

63. Cheung TT, Kwok PC, Chan S, Cheung CC, Lee AS, Lee V, et al. Hong Kong consensus statements for the management of unresectable hepatocellular carcinoma. Liver Cancer 2018;7:40-54.

64. Sapisochin G, Barry A, Doherty M, Fischer S, Goldaracena N, Rosales $R$, et al. Stereotactic body radiotherapy vs. TACE or RFA as a bridge to transplant in patients with hepatocellular carcinoma. An intention-to-treat analysis. J Hepatol 2017;67:92-99.

65. Bruix J, Sherman M, American Association for the Study of Liver Diseases. Management of hepatocellular carcinoma: an update. Hepatology 2011;53:1020-1022.

66. Bush DA, Smith JC, Slater JD, Volk ML, Reeves ME, Cheng J, et al. Randomized clinical trial comparing proton beam radiation therapy with transarterial chemoembolization for hepatocellular carcinoma: results of an interim analysis. Int J Radiat Oncol Biol Phys 2016;95:477-482.

67. Huo YR, Eslick GD. Transcatheter arterial chemoembolization plus radiotherapy compared with chemoembolization alone for hepatocellular carcinoma: a systematic review and meta-analysis. JAMA Oncol 2015;1:756-765.

68. Jeong Y, Shin MH, Yoon SM, Song GW, Kim KH, Ahn CS, et al. Liver transplantation after transarterial chemoembolization and radiotherapy for hepatocellular carcinoma with vascular invasion. J Gastrointest Surg 2017;21:275-283.

69. Vogel A, Cervantes A, Chau I, Daniele B, Llovet JM, Meyer T, et al. Hepatocellular carcinoma: ESMO clinical practice guidelines for diagnosis, treatment and follow-up. Ann Oncol 2018;29(Suppl 4):iv238-iv255. 